\title{
PIETER VERMEULEN
}

\section{Upstaging the "Death of the Subject"}

\author{
Gertrude Stein, the Theater, and the Self-Differential Self
}

\begin{abstract}
While Gertrude Stein is often celebrated as a proto-postmodernist whose formal experiments destabilize traditional notions of subjectivity, a reading of her little-discussed Lectures in America reveals that her poetics actually relies on the anxious suppression of the threat of the loss of a sovereign form of subjectivity. Following Rei Terada's distinction between subjects and "self-differential selves," it can be shown that Stein's theory of the emotions and her account of the emergence of her poetics theorize the theater as the site of an inescapable encounter with the self's difference from itself. By deploying an elaborate rhetoric of the uncanny, the lectures aim at containing the threat of the loss of a strong subjectivity by locating it in the theater alone.
\end{abstract}

\section{I.}

If we can safely say that the much-taunted "death of the subject" is now a thing of the (recent) past, it is less easy to determine the precise place of the subject in the fields of literary and cultural studies today. The challenges to the subject that were articulated by the likes of Derrida, Kristeva, and Deleuze have been met by the resurrection of the individual, of notions of personal and collective agency, and of identity. Such strategies generally do not simply consist in an outright return to undeconstructed notions of subjectivity, but more modestly aim to retrieve or reconstruct some of the elements that the dying subject threatened to take away with it. When we look at such well-publicized phenomena of the last two decades as the success of (auto)biographical writing or the increasingly acknowledged importance of ethnic or national belonging, we see that they are often understood, if not as a refutation, then at least as a welcome correction to the "death of the subject." The feeling that such amendments and reparations to the post-structuralist dismissal of the subject are long overdue reveals a shared conviction that when we let go of the subject, then together with the subject, we are losing considerably more: personal responsibility, ethical accountability, consciousness, interiority, emotions and affects, or even the possibility of experience as such. If all these things are assumed to depend on an enduring 
subject, it is no surprise that many have clamored for some kind of subjectivity, though its more modest and chastised version will not be a sovereign and autonomous subject.

Still, the fear that the abandonment of the subject would entail the loss of a vast range of experiences does not underlie the whole range of reactions to the post-structuralist challenge to the subject. Indeed, there was also a more celebratory and affirmative tendency in postmodern thought that did not lament the demise of the subject and of a whole gamut of experiences, but that rather considered the removal of the subject to be the very possibility condition for genuine experience. This position - perhaps most famously embodied in the work of Jean-François Lyotard - holds that it is because the discourses of antihumanism or post-structuralism have deposed the subject from its position of sovereignty that a "more wordly, more concrete, more pluralistic, more differentiated" mode of experience becomes possible (Critchley and Dews 12). The subject was not the instance that enables experience; it is now considered as an obstacle that has to be removed in order for genuine experience, difference, and emotion to become possible at all. Genuine experience, for this more affirmative kind of postmodern thought, can only occur when we have let go of the subject. There is no reason to mourn when the subject is declared to be dead -we need to welcome the chance to finally begin the real life that subjectivity has always denied us.

In her prize-winning book Feeling in Theory: Emotion after the "Death of the Subject" (2001), Rei Terada puts forward the bold argument that both classical and post-structuralist thought contain a theory of the emotions that considers them as non-subjective. Terada takes issue with the prevalent idea that people like Derrida and de Man are simply not concerned with emotion because they let go of the subject. On the contrary, Terada shows, their work is surprisingly continuous with a classical "discourse of emotion" that began with Descartes and "describes emotion as non-subjective experience in the form of self-difference within cognition" (3). This subversive dimension is often obscured in classical thought because the disruptive force of emotion is routinely contained by what Terada calls an "ideology" of emotion, a defensive move in which emotion is used to remedy the disruption of subjectivity that it has caused. When this ideology discovers that emotion disrupts the subject's autonomy, it redefines emotion as the expression of a subject and thus immediately cancels emotion's radically nonsubjective status. More recent theory, in contrast, capitalizes on this radicality; according to Terada, the work of Derrida, Deleuze, and others is about emotion to the precise extent that it holds on to the death of the subject. Emotion occurs "as a differential force within experience" (9), and as such escapes (and contests) the control of the subject. Terada's book is an impressive rejoinder to theorists like Fredric Jameson who hold that after the death of the subject no real feeling or genuine experience is possible anymore "since there is no longer a self present to 
do the feeling" (qt. Terada 2). What remains after the subject is, according to Terada, "self-differential selves" (155) who, to the extent that they are not subjects, are capable of feeling. Emotion can only occur where the subject differs from itself.

While Terada thus dispels the fear that no emotion or no valuable experience will be possible after the death of the subject, the differential force she registers cannot be celebrated all that simply as a breakthrough to a decidedly nonsubjective postmodernism. This essay tests the temptation to engage in such a celebratory overcoming of subjectivity by focusing on one literary example: the work of Gertrude Stein. Her status as a proto-postmodernist and as a precursor of work inspired by French feminism is a critical commonplace. ${ }^{1}$ Marianne DeKoven, whose 1983 book A Different Language was instrumental in claiming Stein as "one of the great foremothers" of second-wave feminism, has underlined the affinity between post-structuralism and Stein's "semiotic, pre-Oedipal, antipatriarchal experimental forms" ("Introduction" 473). Stein's linguistic experiments challenge patriarchal domination to the extent that they resist reduction to any "sensible, coherent, unitary meaning" (476). In this feminist line of reception, Stein's challenge to meaning and subjectivity is mobilized for the construction of a different subjectivity - what DeKoven calls "a capacious alternative subjectivity" (478).

When the celebration of Stein as the "grandmother of postmodernism" is not explicitly linked to a feminist agenda, and thus not recuperated for a modified kind of subjectivity, the postmodern reception of her work generally emphasizes its formal and experimental resistance to subjectivity. Stein's proto-postmodernism is most famously monumentalized by her inclusion in Jean-François Lyotard's postmodern classic The Differend. Lyotard writes that in Stein's work "the feeling or the sentiment is the linkage, the passage" (67). In Stein's peculiar poetics, feeling does not reside in isolated blocks of meaning (sentences) but is generated by the indeterminate passage between them. For Stein, it is crucial "that sentences are not emotional and that paragraphs are" (P xxix). ${ }^{2}$ The next section of this essay uses Steven Meyer's Irresistible Dictation (2001) to show how her modernist poetics contains a non-subjective theory of the emotions that has remarkable affinities with the post-structuralist position expounded by Terada. I then turn to a number of Stein's little-discussed "Lectures in America," especially to the lecture "Plays," in order to trace Stein's own surprising account of the genesis of the self. A close reading of these lectures makes clear that the postsubjective experience that is often celebrated in postmodern discourses does not

${ }^{1}$ For a helpful overview of critical work that characterizes Stein's language as postmodern, see the first note in Jennifer Ashton's article.

2 References to the following texts by Stein are preceded by the abbreviations between brackets: "Plays" (P), "What is English Literature" (WEL), and "Portraits and Repetition" (PR), which is found in Writings and Lectures 1911-1945. 
consist in a lucid acceptance of non-subjectivity, but instead relies on an unacknowledged defensive reaction that protects the subject precisely against the threat of non-subjectivity. Stein's surprising genealogy shows that the celebration of the death of the subject is an attempt to preserve the illusion of sovereignty that is not all that different from the different reconstructions of subjectivity to which the affirmation of the death of the subject is often opposed. As we will see, this also problematizes the feminist recuperation of Stein's language. The rhetoric of the "death of the subject" is a strategy to hold on to the belief that we can ever be more than self-differential selves, that we can somehow be fully rational and sovereign subjects. Quid non.

\section{II.}

Steven Meyer's Irresistible Dictation: Gertrude Stein and the Correlations of Writing and Science situates Stein's literary work in relation to the scientific research she conducted around the turn of the century in the Harvard Psychological Laboratory and at Johns Hopkins Medical School. This approach allows Meyer to make sense of Stein's "discovery," which is central to her "poetics of grammar," that "sentences are not emotional and that paragraphs are." Meyer situates Stein's discovery in relation to the "radical empiricism" that Stein adopted from the philosopher William James, with whom she collaborated at Harvard. The difference between (unemotional) sentences and (emotional) paragraphs can be mapped onto James' radical empiricist distinction between sensations and emotions. For James, emotion is not simply the summation of a set of sensations, but rather the experience of a particular "succession" of sensations. Meyer writes:

Just as "emotional paragraphs" were "made up of unemotional sentences," emotions were composed of unemotional sensations [...] Stein recognized [...] that sentences and paragraphs were related in exactly the same way that sensations and emotions were; indeed, her thesis concerning the emotional nature of paragraphs was itself a variation on James's theory of emotion, only extended to writing. (281)

Just as sensation, as bodily and physiological experience, is not in itself emotional, so sentences, in Krzystof Ziarek's words, "as the basic units of writing, have to be seen not in grammatical terms but as the open-ended events of meaning" that in themselves do "not give off emotion" (Ziarek 131). The emotion is only experienced in the sentences' "nonprogressive" "succession" (Meyer, Irresistible 275-81). The linkage of sentences enables an immediate emotional experience that the individual sentences cannot deliver in isolation. In the words of Don Byrd, for Stein "the immediacy of language is not the immediacy of self-presence but the immediacy of difference as measure" (181). 
For Stein, emotion is not a matter of cognition, of self-presence, or of meaning. Emotion occurs in the event of transition, in the gaps between meaningful propositions. This fits Terada's definition of emotion as "non-subjective experience in the form of self-difference within cognition" (3). Meyer notes that the discovery of the irreducibility of emotion to cognitive representation marks Stein's difference from her teacher William James: whereas " $[t]$ he account of representation he relied on was essentially interpretative," Stein (following Emerson here) locates emotion in the linkage between the units of representation, in the non-interpretative "astronomical interspaces" "betwixt atom and atom"; Stein's poetics explores "the inter-, not inner, spaces of words" (Meyer, "Writing Psychology Over" 137-38). Within the paragraph, the emotion resides precisely in the differential interspaces - which are not open to cognitive interpretation - between the representational units making up the paragraph. This emotional investment in the non-interpretable qualifies Stein's modernism as a non-subjective theory of the emotions.

So far so good. In her lecture "Plays," Stein begins with the "fundamental" discovery "that paragraphs are emotional and sentences are not," only to go on to state "a fundamental thing about plays." Here is that fundamental "thing," in Stein's idiosyncratic but always entirely lucid prose:

That something is this.

The thing that is fundamental about plays is that the scene as depicted on the stage is more often than not one might say it is almost always in syncopated time in relation to the emotion of anybody in the audience.

What this says is this.

Your sensation as one in the audience in relation to the play played before you your sensation I say your emotion concerning that play is always either behind or ahead of the play at which you are looking and to which you are listening. So your emotion as a member of the audience is never going on at the same time as the action of the play. (P xxix)

The first thing to remark here is that the analogy between sensation and emotion on the one hand and (representational) sentence and (non-representational) linkage on the other breaks down in the case of plays. Stein equates sensation and emotion ("your sensation I say your emotion") and places it in relation to "the scene as depicted on the stage" - the scene, that is, as an explicitly representational act. Wheareas emotion in Stein's "poetics of grammar" consists in an escape from representation, in the theater emotion derives from the explicitly representational status of the thing inspiring emotion. The differential moment does not here consist in the transition between sentences, but rather in the syncopation between the action depicted on the stage and the emotion of the subject witnessing that action.

As the rest of Stein's lecture makes clear, this a-synchronicity ties in with a further distinction that is introduced when she refers to "the play at which you 
are looking and to which you are listening." Looking (or seeing) and listening (or talking) have, for Stein, very different temporalities. For Stein, "seeing" is complicit with repetition, resemblance, and memory, and as such threatens the immediacy and intensity of emotion that her poetics requires; "listening," on the other hand, is on the side of what Stein calls "insistence" (PR 99). In a contemporaneous lecture, Stein notes that "[l]istening and talking did not presuppose resemblance and as they do not presuppose resemblance, they do not necessitate remembering" (103). Looking, on the other hand, "inevitably carried in its train realizing movements and expression and as such forced me into recognizing resemblances, and so forced remembering and in forcing remembering caused confusion of present with past and future time" (111).

It is remarkable that seeing is here demoted for its lack of immediacy for "forcing" the subject to remember. In the light of Stein's poetics of grammar, and its affinities with a non-subjective theory of emotion, we might have expected that she would have welcomed the capacity to generate self-difference within the subject as a source of genuine non-subjective emotion. Instead, Stein downgrades it. We may well ask, then, how this difference between Stein's radical poetics of grammar and her theory of the theater is to be explained. As I noted, the main difference between writing and the stage is that in the theater, we are unavoidably aware that we are witnessing an act of representation. This suggests that there is something in representation that forbids the celebration of the nonsubjective self we find in Stein's poetics of grammar. A discussion of Stein's lectures makes clear that the postmodern celebration of non-subjective emotion - and of Stein as a precursor to such a position - has overlooked that, on Stein's own account, her theory of the emotions is already a defense against the fear of the subject's basic difference from itself.

III.

In order to make sense of Stein's lectures in America, it is vital to understand their place in her career. Stein delivered these lectures after the publication of The Autobiography of Alice B. Toklas (1933) brought her overnight fame and ended a period in which her work went largely unrecognized. Stein's remark about the non-coincidence between the play and its audience can be seen as a reference to the weak reception of her literary work before 1933 . Stein had already situated this lack of public attention in the same terms in her 1926 lecture "Composition as Explanation," when she talked about an inescapable "syncopation" between a masterpiece and its initial audience (Kaufmann 226). Stein's account in the lectures of her own art and of her views on art and literature can then be understood as an attempt to close the temporal gap between her art and her audience. For Stein, "talking" (as in the lectures) "essentially has nothing to do 
with [the] creation" of masterpieces (Writings and Lectures 146) - which means that the lectures do not have to suffer the fate of syncopation. And because they can communicate directly to an audience, they allow Stein to establish "a postrupture identity" (Knight 159). The lectures are belated attempts at synchronization in which Stein authoritatively comments on her own artistic practice.

Stein presents her own positions not as truths arrived at by logic, but rather as options chosen (Knight 162). One such self-conscious choice is Stein's decision to equate emotions with sensations in order to mark the difference between the theater and her poetics of grammar ("your sensation I say your emotion"). In the theater, the vital distinction is no longer between sensation and emotion, but between "the thing seen and the thing felt about the thing seen" (P xxx, italics mine). While the theater is thus defined by its explicit representationality, by its inescapable reference to other signs and realities, whatever it represents still acquires the stability of a "thing." "Plays" is not the only lecture in which the tendency to deny the inevitable secondariness of signs brings Stein to consider the sign as itself "a thing." In her contemporaneous lecture "What is English Literature," which offers a miniature history of English literature that unsurprisingly culminates in America ${ }^{3}$, "the thing" serves as a technical term that propels the narrative forward. Stein explicitly defines the denial of the secondariness of the sign as the very condition for the successful creation of what she calls "Americanness" or "newness" (Riddel 84-86). America differs from England in that it lacks a sense of "daily living," and this frees its literature from the obligation to refer to daily life: "It tells something because that anything is not connected with what would be daily living if they had it" (WEL 54). It is "the disembodied abstract quality of american character" that allows Stein to define the sign as a self-contained thing and to deny its secondariness in relation to other signs or to an outside reality.

Stein positions the abstractness and self-sufficiency of the American character at the outcome of a literary history that begins in the English Middle Ages. Medieval England was as self-sufficient as contemporary America is, not because there was no "daily living" to refer to, but rather because the things medieval literature dealt with were so much a part of daily life: "England is so much what it is, it is the poetry of the things with which any of them are shut in in their daily, completely daily island life" (34). For medieval English poetry, the whole province of life ("birds beasts woods flowers, roses, violets and fishes") could become "the thing." The rest of the history of English literature is then the story of a progressive shrinking of "the thing" literature deals with, until the sign itself becomes the thing. Stein narrates how, after the Middle Ages, word choice for the Elizabethans became "the thing" $(38-39)$, then the sentence became the

\footnotetext{
${ }^{3}$ See Schoenbach 249-53 for a good contextualization of this lecture.
} 
"completed thing" (49), later "phrases became the thing" (50), and then "slowly the paragraph came to be the thing" (53).

This curious move from the whole of life to a purely linguistic thing that no longer refers to daily life occurs in different stages, which are all triggered by a similar realization: the shocking perception that the previous narrowing down of the circle of literary "things" is insufficient, and cannot exclude the traces of what it believed to have locked out. Word choice became the Elizabethan thing when "the outside separation [...] had come to be an inside separation" (38). In the nineteenth century, "[t]he daily island life was not sufficient any more as limiting the daily life of the English," and "the fact that the daily living was ceasing to be quite so daily" led to the shift from phrase to paragraph (52-53). The reason for these moves is thus the awareness that a foreign element has intruded in what was taken to be a homely and neatly cordoned-off inside. Each step in the history of Anglo-American literature appears to be motivated by the perception of the representational dimension of literature - of the fact that literary signs refer to other signs and other realities. It is only America's "disembodied way of disconnecting something from anything and anything from something" that creates, at the end of Stein's story, the required division between inside and outside (56).

There is another remarkable parallel between "Plays" and Stein's literary history. The move preceding that from phrases to paragraphs, i.e., the move from sentences to phrases (or from the eighteenth to the nineteenth century), is cast in terms that are remarkably similar to what Stein, in "Plays," called "the problem" of "syncopated time," of "needing to go faster or to go slower so as to get together" (P xxx). Daily life was interrupted by wars and catastrophes, and

there is something you must always remember about wars that is about catastrophes, they make a change which is a change which is about to be a change go faster as much faster as a war can go, and even a slow war a slow catastrophe goes quite fast. (WEL 46)

The syncopation between the habits of everyday life and the catastrophes that invade life brings home the lesson that the "inside" cannot be seamlessly cordoned off from the outside, and that the previous attempt to make the sign into the thing cannot ward off the uncontrollable representational nature of language. The move from the sentence to the phrase is one more defense against the perceived representationality of language. When we use this anxiety about representationality to map the movement from the theater to Stein's poetics of grammar, this suggests that the valorization of the "emotional" paragraph can be understood as a defensive reaction to the essential representationality of language that reveals itself in the theater. ${ }^{4}$

${ }^{4}$ Jacques Lezra has pointed out that, because Stein developed her distinction between sentences and paragraphs in a period in which she was very self-consciously forging her own public image, these aspects should be considered together (Lezra 118). Also, it is important to point out that the 
IV.

So what is so special about the theater? Most trivially, perhaps, that it differs so markedly from the real life to which it inevitably refers. "Plays" again defines the difference between theater and real life as a difference in temporality. In "real life," "one progresses forward and backward" (P xxxii-xxxiii), while in the theater "the emotion of the one seeing and the emotion of the thing seen do not progress together," and this results in a certain "nervousness" ( $\mathrm{xxx})$. This "nervousness" is not celebrated as a (proto-postmodern) insight into the non-subjective nature of emotion, but is instead treated as a problem to be solved (xxxv). Real life, for Stein, provides "completion": "in the real thing it is a completion of the excitement" (xxxi, italics mine), which resembles nothing so much as the "completely completed" dailiness that Stein attributed to medieval England (WEL 36). One thing is required for real-life completion to be possible: the "climax of completion" is only possible when others "feel act and talk including yourself differently from the way you would have thought that they would act feel and talk" (P xxxvii). What we need is the capacity to be surprised.

In Stein's logic, such surprise is only possible from what she calls a "standpoint of familiar acquaintance" (with ourselves as well as with others) that is acquired in a process of "progressive familiarity" (xxxviii). This gradual familiarization, for Stein, is what is going on in real life. What is more remarkable is the radical split between this gradual progress, which Stein considers as the normal course of things, and the theater, which Stein sees as decidedly abnormal:

But we may say that the exciting experience of exciting scenes where you have really no acquaintance with the other actors as well as none with yourself in an exciting action are comparatively rare and are not the normal material of excitement as it is exciting in the average person's experience. (xxxvii)

In Stein's argument, everything that does not conform to this picture of the average and the normal is removed from the realm of real life and consigned to the theater. Such exclusions of the rare and the abnormal can all too easily be recognized as what Jacques Derrida used to call a relation of supplementarity, in which the unwelcome features of a particular situation are displaced to a space that can be dismissed as abnormal and irrelevant. Stein's decision to relegate to the theater all encounters that do not take the form of a progressive familiarization also recalls a similar move in the work of J.L. Austin, on which Derrida famously commented in his essay "Signature Event Context." While Austin considered speech on stage as a non-serious use of language, and therefore as

lecture-context constituted a constraint on Stein's normal practice, which, as many critics have pointed out, aimed precisely to reconfigure the discursive context in which her works were received (an aim which the inflexible protocols of lecturing made hard to achieve). See especially Monroe and Tate for discussions of the reconfigurative ambitions of Stein's work. 
irrelevant to his speech act theory, Derrida famously maintained that "[f]or me to be able to make a promise in 'real life,' there must be iterable procedures or formulas, such as are used on stage. 'Serious' behavior is a special case of roleplaying" (Culler 119).

The stage, far from being an irrelevant exception to real life, presents instead the secondariness and non-originality of life in its most explicit form. This explains Stein's defensive posturing in relation to the theater. "Plays" proceeds as if real life constitutes the default situation from which the theater "parasitically" takes off. It imagines real life as a realm of purity and stability by relegating the threat of secondariness to the theater, and to the theater only. In the theater, Stein writes, "you have the disadvantage of not knowing the difference between hearing and seeing and is that a disadvantage from the standpoint of remembering. From the standpoint of remembering it is a serious disadvantage" (xxxvii). It is serious, because it prevents real-life completion: "each time you cannot get completion, but you can get relief and so already your memory of any exciting scene in which you have taken part turns it into the thing seen or heard not the thing felt" (xxxii). Like theater, memory only affords "relief from the excitement," and this relief is opposed to the "real presentation" of "real life" (xxxi).

Memory and the theater prevent real-life completion because they "force" the subject and lead to confusion and a loss of control (PR 111). Involuntary memory and the theater confront the self with a moment of self-difference, and this event is not celebrated as an occasion of non-subjective emotion, but rather anxiously compensated for by the introduction of a different type of memory. This is the sort of movement typical of what Terada calls the ideology of emotion - a movement in which emotion is called upon to tell "a supplementary story in which [it] fills in the difference it registers" (3). In "Plays," this takes the form of a narrative that moves from the threat of involuntary memory to a different kind of memory that the subject can control. Stein tells the story of her developing relation to the theater, which unsurprisingly begins with a failure of memory: "Uncle Tom's cabin may not have been my first play but it was very nearly my first play." This experience is only remembered as a disturbing emotion: "I only remember that it felt like a theatre that is the theatre did" $(\mathrm{P} \mathrm{xl})$. The emotion thus registers a moment of "self-difference within cognition" (Terada 3); the experience of uncertain memory and of an unsettling encounter with the stage is acknowledged, only for memory to go on to tell a supplementary story in which it compensates for the self-difference it has revealed.

At the culmination of Stein's story the "I enormously remember[s]" when the fully realized subject "first felt two things going on at one time" (xli). The achievement of a memory that is fully controlled by a sovereign subject (Caramello 4) is the telos of a story in which the self first "gradually saw more" because she "saw it quite frequently" ( $\mathrm{P} \mathrm{xl})$, before it manages to register "sound," which 
is also acquired through a process of repetition: it depends on an actor's "repeated calling out, Nemours Nemours" (xli). The story of the self's (Stein's) increasing control over her memory, and thus of her progressively successful correction of the threat of non-subjective experience is paralleled by a story of how the strengthened subject manages to break away from her (Stein's) father to finally brave the theater "a great deal alone" (xli). ${ }^{5}$ Unsurprisingly, this achievement of a sovereign subjectivity is described in terms that echo the movements of internalization that organized Stein's history of English literature: Stein asserts her autonomy by "making an outside inside existence for me," which allows her to regain the enjoyment of "daily life" (xli). Whereas involuntary memory earlier returned one to "the thing seen or heard not the thing felt" (xxxii), and therefore established a relation to an outside ("the thing seen or heard"), this sovereign form of recollection allows the subject to go back in feeling, without having to face anything external. This kind of recollection is, in Claudia Franken's words, a "warm remembering" that enables "a 'reestablishment' of the self as released from the sense of being stretched along a temporal line" $(215,221)$. With the subject blissfully suspended in the self-identical now, the theatrical threat of syncopation is, at the end of Stein's narrative, finally laid to rest. Emotion, far from disrupting the sovereignty of the subject, has become an attribute that affirms the subject's self-control. And while Stein's narrative seemed to harbor the hope of feminine self-assertion at the moment when she let go of her father in order to face the theater alone, this self-assertion soon restores the robust and masculinist form of subjectivity from which it departs.

V.

We need to retrieve one more aspect of Stein's lectures in order to name the threat that informs her defensive construction of subjectivity. In Stein's account of the emergence of her subjectivity, her capacity to see preceded her ability to hear. This is remarkable, because, as I noted above, seeing implies for Stein repetition and resemblance; unlike hearing, it is a form of perception that risks exposing the self to syncopation. Yet seeing only constitutes the more threatening kind of perception when we perceive human beings. So Stein writes in "Portraits and Repetition: "I made portraits of rooms and food and everything because there I could avoid this difficulty of suggesting remembering more easily while including looking while listening and talking than if I were to describe human beings" (PR 111). In human interaction, "sight sound and emotion" cannot be

\footnotetext{
${ }^{5}$ For the role of such oedipal moments in Stein's theory of subjectivation in The Making of Americans, see Watten.
} 
synchronized (P xxxvii). The threat that Stein attributes to the activity of seeing and to the theater thus particularly concerns human beings.

So what are the elements that constitute the threat that underlies Stein's lectures? Stein, especially in "What is English Literature," valorizes the capacity to construct a linguistic enclosure cordoned off from the disturbances of daily life; this is connected to a dismissal of representationality and non-originality, a threat that proves to be essentially connected to human beings; Stein further imagines a "normal" scenario in which we progressively get to know both others and ourselves. When we put these elements together, we get a quite accurate picture of "the problem" to be solved in Stein's lectures: the threat - exemplarily confronted in the theater - is an encounter with an explicitly self-differential other human being who cannot be exteriorized. Since it cannot be exteriorized, this other threatens our own sovereignty, and raises the suspicion that we ourselves are not full-fledged subjects, but rather merely representational, self-differential, emotional selves. Because the theater draws attention to "the scene as depicted," it epitomizes the danger of what she calls "inside separation" in "What is English Literature."

In order to understand Stein's recourse to a strong notion of subjectivity to ward off the threat of the self's difference from itself, it is useful to return to Terada for a moment. The truth of the discourse of emotion, for Terada, is that it acknowledges that self-difference. Far from implying the end of human life and of the subject, it in fact shows how living systems are always self-differential, and how "experience is experience of self-differentiality" (155). Talk of the "death of the subject" is then an attempt to ward off that awareness and to hold on to the figure of a masculine, self-identical, sovereign subject (even if that subject is now dead). Yet as Terada writes, "[s]elf-differential selves are dead only as subjects; they are not dead as self-differential selves" (154). Self-difference is where we are. In order to illustrate historical philosophical defenses against the discovery of "the non-subject - the functional but self-differential being" (154), Terada invokes the philosopher Daniel Dennett's discussion of the zombie. The mobilization of zombies reflects the anxiety that it may well be impossible to tell the difference between an automaton and a fully conscious human being. Terada's point is that such a fully-centered and perfectly rational consciousness simply does not exist, and that there is no need to see this as a great loss, let alone to invent zombies in order to perpetuate the fantasy that fully autonomous beings could somehow exist. Returning to Stein's lectures, we can see that they approach the insight that we are all self-differential selves, but in the end deny that knowledge by yet erecting the fiction of a sovereign subject.

The threat that motivates both Stein's narrative and the philosophical fiction of the zombie comes close to the figure of the uncanny. Freud's seminal text on the uncanny has famously been read as its own metaphor (by Hélène Cixous), or as an attempt by Freud to evade the connection between the uncanny and 
intellectual uncertainty, i.e., self-difference within cognition. In her discussion of Freud's text, Sarah Kofman reminds us that it is primarily concerned with E.T.A. Hofman's story Der Sandmann: the sandman "is above all an intruder who puts an end to the security of the family group, who disrupts the intimacy of the proper and the near" (155). The indistinguishability of the famous automaton from a "conscious" self recalls Dennett's zombie-metaphors, as well as Stein's evasions: "Perfection is thus the sign that one is dealing with a machine which is mimicking life [...] The double is neither living nor dead" (Kofman 148). And to further underline the connections between Freud and Stein, consider how Kofman also connects the fear of the automaton to the pervasiveness of representation and the absence of a stable origin: "The importance of doubles [...] stems from [the] first substitution of the act by its representation: an originary representation that takes the place of an always forbidden presence" (152). Hence, "there can be no instance of the uncanny that does not always already imply repetition" (137). In Freud, as in Stein, representationality comes to invade a canny inside, and this intrusion raises the specter of the self's own non-subjectivity.

\section{VI.}

Stein's lectures suggest that an oeuvre that is often celebrated as exemplarily nonsubjective relies on the suppression of self-difference and the reaffirmation of a strong form of subjectivity. Terada's discussion of the "death of the subject" in its turn makes clear that the postmodern strategy of declaring self-differential selves to be "dead" subjects (substituting "the image of the corpse for the concept of self-difference"; 155) is similarly inspired by the hope to preserve the illusion that there are subjects who do not differ from themselves and are in full control of their lives. Mourning the death of the subject or celebrating our liberation from it are then but two strategies that allow us to go on as if there were fully sovereign selves. These postures do not change the fact that there are - that we are - only ever self-differential non-subjects.

At certain moments, Stein's work comes very close to acknowledging the complementarity of the death and the re-affirmation of the subject. In the important lecture "Sentences and Paragraphs," we read:

What is a sentence. A sentence is a duplicate. An exact duplicate is depreciated. Why is a duplicated sentence not depreciated. Because it is a witness. (35)

This depreciation of exact duplication reminds us of the familiar uncanny anxiety about the impossibility of telling a conscious self apart from an automaton. The "sentence" is here redeemed precisely because it is not "an exact duplicate." Instead, it is "a witness" to an event of non-exact repetition, an event in which something is lost. The sentence, that is, does not lead to the strong 
subject's comfortable "form of recollection" by means of which we experience "a feeling freed from remembrance without any sense of loss or "reduction"” (Franken 221). Such a "canny" form of memory is finally achieved in "What is English Literature," where the loss that is preserved in the sentence is relieved by the linguistic unit that collects these sentences, the paragraph: "Paragraphs are emotional not because they express an emotion but because they register or limit an emotion" (WEL 53). The emotion elicicited by the paragraph relieves us from the losses carried along by the sentences.

On the stage a similar relief from language's representationality is impossible. Here, relief will require a more violent movement than the mere composition of sentences into a paragraph. In "Plays," Stein talks about the time Sarah Bernhardt came to San Francisco. The performance in French surprisingly did not seem to inspire the nervousness the theater normally occasions: with Bernhardt, "it all being so french I could rest in it untroubled," which "was better than the theatre because you did not have to get acquainted" (P xlii). French is sufficiently foreign to the (Anglophone) subject for that subject not to have to fear it. Sarah Bernhardt's performance leads to no "inside separation," but merely to an "outside separation" that does not "produce confusion" (WEL 37-38). And just as Bernhardt's French does not threaten Stein's subject construction, so in "What is English Literature," the Norman invasion does not lead to an uncanny unsettling of medieval England's composure: "The thing that happened before Chaucer, the norman conquest coming as it did from the outside was one of those things which as I say do not produce confusion" (37).

At the end of "Plays," Stein writes about her practice of making plays approximate landscapes: "I found that since the landscape was the thing, a play was a thing and I went on writing plays a great many plays" (P xlvi). The thing-ness of landscapes and of plays resembling landscapes positions them safely outside the subject: "I felt that if a play was exactly like a landscape then there would be no difficulty about the emotion of the person looking on at the play being behind or ahead of the play because the landscape does not have to make acquaintance" (xlvi). So even "if you look at it" (xlvi), the play now no longer conveys a threatening representationality and can be approached by the subject in its own time, without the interference of "the repetition time of remembering" (PR 106); it can be approached within the time of progressive familiarity.

Stein concludes her lecture with the example of her play "Four Saints" in which she "made the Saints the landscape." In order to explain this achievement, Stein turns to the medium of photography, which allowed her to see the Saints "as well as feel them" (li). This is the curious anecdote that gives the Saints the "actuality" Stein needed to be able to write the play:

As it happened there is on the Boulevard Raspail a place where they make photographs that have always held my attention. They take a photograph of a young girl dressed in the costume 
of her ordinary life and little by little in successive photographs they change it into a nun. These photographs are small and the thing takes four or five changes but at the end it is a nun and this is done for the family when the nun is dead and in memoriam. (li)

The succession of photographs triggers a process of progressive familiarization, and this allows their "warm" recollection by a sovereign subject. Yet as this passage acknowledges, such recollection, and such strong subjectivity, are only possible when another self is declared dead - when, in other words, a selfdifferential self is "dead and in memoriam." Stein's story here comes close to acknowledging that declaring the death of the subject and resurrecting that subject are complementary movements - related ways of preserving the fiction of sovereign subjectivity in the face of the uncomfortable realization that we are all never more than self-differential selves. Stein's story of the theater in "Plays" offers an essential prelude to her poetics of grammar. Her lectures tell the subjective story of the genesis of her alleged non-subjective theory of writing, and it is this story that the routine celebration of Stein as the "grandmother of postmodernism" often remains deaf to. What we gain by listening to this story is the muted voice of the self-differential self that threatens to disappear every time the death of the subject is proclaimed, celebrated, or resisted.

\section{Works Cited}

Ashton, Jennifer. "'Rose is a Rose.' Gertrude Stein and the Critique of Indeterminacy." Modernism/Modernity 9, 2002, 4, 581-604.

Byrd, Don. The Poetics of the Common Knowledge, Albany: State University of New York Press, 1994.

Caramello, Charles. "Gertrude Stein as Exemplary Theorist." Gertrude Stein and the Making of Literature. Ed. Shirley Neuman and Ira Bruce Nadel, Boston: Northeastern University Press, 1988. 1-8.

Cixous, Hélène. "Fiction and Its Phantoms. A Reading of Freud's Das Unheimliche." New Literary History 7, 1976, 3, 525-48.

Critchley, Simon and Peter Dews. "Introduction." Deconstructive Subjectity. Ed. Simon Critchley and Peter Dews, Albany: State University of New York Press, 1996, 1-12.

Culler Jonathan. On Deconstruction. Theory and Criticism after Structuralism, Ithaca: Cornell University Press, 1982.

DeKoven, Marianne. A Different Language. Gertrude Stein's Experimental Writing, Madison: University of Wisonsin Press, 1983.

— . "Introduction. Transformations of Gertrude Stein." Modern Fiction Studies 42, 1996, 3, 469-83.

Derrida, Jacques. "Signature Event Context.” Glyph 1, 1977, 172-97.

Franken, Claudia. Gertrude Stein. Writer and Thinker, Münster: LIT, 2000.

Kaufmann, David. "Desperate Seriousness and Avant-Garde (Mis) Recognition in Some of Stein's Sentences.” Modern Philology 97, 1999, 2, 220-33. 
Knight, Alan. "Masterpieces, Manifestoes, and the Business of Living. Gertrude Stein Lecturing." Gertrude Stein and the Making of Literature. Ed. Shirley Neuman and Ira Nadel, Boston: Northeastern University Press, 1988, 150-167.

Kofman, Sarah. Freud and Fiction. Trans. Sarah Wykes, Cambridge: Polity Press, 1991. Lezra, Jacques. "How to Read How to Write." Modernism/Modernity 5, 1998, 1, 117-29. Lyotard, Jean-François. The Differend. Phrases in Dispute, trans. Georges Van Den Abeele, Minneapolis: University of Minnesota Press, 1988.

Meyer, Steven. "Writing Psychology Over. Gertrude Stein and William James." The Yale Journal of Criticism 8, 1995, 1, 133-63.

- . Irresistible Dictation. Gertrude Stein and the Correlations of Writings and Science, Stanford: Stanford University Press, 2001.

Monroe, Jonathan. "Syntextural Investigations." Diacritics 26, 1996, 3-4, 126-41.

Riddel, Joseph. The Turning World. American Literary Modernism and Continental Theory, Philadelphia: University of Pennsylvania Press, 1996.

Schoenbach, Lisi. “Peaceful and Exciting.' Habit, Shock, and Gertrude Stein's Pragmatic Modernism." Modernism/Modernity 11, 2004, 2, 239-59.

Stein, Gertrude. "Sentences and Paragraphs." How to Write, Barton: Something Else Press, 1973. 23-35.

- . "Plays." Last Operas and Plays. Ed. Carl van Vechten, Baltimore: Johns Hopkins University Press, 1995, xxix-lii.

- . Writings and Lectures 1911-1945. Ed. Patricia Meyerowitz, London: Peter Own, 1967.

Tate, Allison. “A Semblance of Sense. Kristeva's and Gertrude Stein's Analysis of Language." Language and Communication 15, 1995, 4, 329-42.

Terada, Rei. Feeling in Theory. Emotion after the "Death of the Subject," Cambridge, Mass.: Harvard University Press, 2001.

Watten, Barrett. "An Epic of Subjectivation. The Making of Americans." Modernism/ Modernity 5, 1998, 2, 95-121.

Ziarek, Krzystof. "The Poetics of Event. Stein, The Avant-Garde, and the Aesthetic Turn of Philosophy." Sagetrieb 12, 1993, 3, 125-48. 